\title{
Analysis of Rail Corrugation Characteristics on High-Speed Rail Based on Transient Finite Element Method
}

\author{
Zhiqiang Wang and Zhenyu Lei \\ Institute of Rail Transit, Tongji University, Shanghai 201804, China, E-mail: 1733359@tongji.edu.cn
}

\section{(Received 5 February 2021; accepted 28 June 2021)}

By using the transient finite element method, a three-dimensional wheelset-track coupled rolling contact model for high-speed rail is established, and the rationality and effectiveness of the model are verified by field measurements. Next, the wheel-rail contact stress states and relative slip characteristics are calculated and analyzed to reveal the cause of inner rail corrugation. Then, the vertical vibration acceleration of the rail/wheel is taken as the output variable to study the dynamic responses of the wheelset-track system. Finally, the parameter sensitivity analysis is carried out. The results show that the maximum normal/tangential contact stress between the inner wheel and inner rail is greater than that between outer wheel and outer rail due to the unbalanced load of inner rail caused by the excess superelevation of track structure, which indicates that the unbalanced load of the inner rail may aggravate the development of rail wear, and the rationality of the model established in this paper is verified. The wheel-rail relative slip region on the inner rail side appears periodically, and the distance between the two adjacent slip regions is close to the characteristic wavelength of the measured inner rail corrugation, which illustrates that the periodic variation of slip regions on the inner rail surface plays an important role in the formation of rail corrugation, and the validity of the model is verified. The periodic distribution of wheel-rail relative slip regions on the outer rail surface is not obvious, demonstrating that the outer rail tends to form uniform wear, which is consistent with the fact that the outer rail corrugation is slight in the measured section. The wheelset-track system has been in the process of unstable continuous oscillation in the analysis interval, combined with the analysis results of the wheel-rail relative slip characteristics, it can be concluded that the unstable self-excited vibration of wheelset-track system under the condition of tangential contact force reaching saturation is the main cause of rail corrugation. The dominant characteristic frequencies of vertical vibration accelerations of rail and wheel are all $561 \mathrm{~Hz}$, the corresponding characteristic wavelength $(148 \mathrm{~mm})$ is close to the distance $(150 \mathrm{~mm})$ between the calculated adjacent slip regions, and is also close to the characteristic wavelengths $(125 \mathrm{~mm}$ and $160 \mathrm{~mm})$ of inner rail corrugation, which shows that the resonance phenomenon occurs in the wheelset-track system at the above frequency, thus leading to the increase of dynamic responses of wheelset-track system. The fastener vertical stiffness and wheel-rail coefficient of friction have significant effect on the development of rail corrugation, and the running speed determines the occurrence probability of inner/outer rail corrugation by affecting the track superelevation state.

\section{INTRODUCTION}

With the increase of EMU (Electric Multiple Unit) operation time, the problem of rail wear on high-speed rail is becoming more and more obvious, especially the rail corrugation. Rail corrugation is a periodic wavy irregularity phenomenon that appears along the longitudinal surface of the rail after it has been put into operation for a period of time. For the high-speed rail, the rail surface generally does not appear obvious tangential plastic deformation or contact fatigue, and the depth of the rail corrugation is relatively shallow, which belongs to the wear type corrugation. ${ }^{1}$ The existence of rail corrugation will lead to high-frequency vibration of the high-speed vehicle-track system, shorten the service life of vehicle and track components, increase the cost of line maintenance, and even affect the safety of train operation. Meanwhile, the high-frequency vibration and impact caused by rail corrugation of high-speed rail will significantly increase the wheel-rail noise, affecting passenger comfort and the surrounding living environment. Slight corrugation can usually be removed by grinding, but when the degree of rail corrugation is serious, the rail can only be replaced with the new one, which increases the consumption of human and material resources of relevant railway departments. ${ }^{2-4}$
Scholars around the world have been studying rail corrugation for more than 100 years. Although they have made a lot of achievements in theory and practice, they have not reached a consensus on the formation mechanism of rail corrugation so far, especially the research on rail corrugation of high-speed rail, which has been gradually carried out in recent years. Jiang et al. ${ }^{5}$ established the theoretical model of rail corrugation development on the ballastless track of high-speed rail, reproduced the evolution process of rail corrugation through numerical simulation, and investigated the influence of key parameters of vehicle and track on the development of rail corrugation. The results showed that reducing the stiffness of vehicle primary suspension and increasing the rail hardness were effective measures. Si et al. ${ }^{1}$ constructed a high-speed rail vehicletrack simulation model by using the multi-body dynamics software NUCARS, analyzed the influence of vehicle and track structure parameters on rail corrugation, and found that reducing the unsprung mass and maintaining appropriate fastener damping could effectively delay the development of rail corrugation. Yan et al. ${ }^{6}$ improved the synchronous compression wavelet transform method, analyzed the axle box vibration acceleration of high-speed rail comprehensive inspection vehicle 
from time domain and frequency domain, extracted the instantaneous frequency of rail corrugation, and realized the accurate positioning of rail corrugation and grinding trace section according to the frequency variation characteristics. $\mathrm{Tu}^{7}$ conducted the field test and theoretical analysis on the wheel-rail dynamic effect of EMUs passing at different speeds in the presence of rail corrugation, and concluded that under the same speed condition, the greater the corrugation wave depth, the greater the wheel-rail dynamic effect; under the same wear condition, the greater the speed, the greater the wheel-rail dynamic effect. Considering the influence of the flexible wheelset resonance mode, Guo et al. ${ }^{8}$ studied the effect of rail corrugation on vehicle dynamic performances. $\mathrm{Li}$ et al. ${ }^{9}$ systematically investigated the relationship between abnormal response characteristics of wheel-rail force and track diseases by analyzing the measured data. The results illustrated that rail corrugation could cause continuous large and high-frequency wheelrail vertical force, so it was more appropriate to evaluate rail corrugation from the perspective of energy accumulation. Cai and $\mathrm{Chi}^{10}$ optimized the sliding window method with the least square technique to simulate the process of vehicle running along the infinite track. Through the numerical simulation of dynamics model and test results analysis, the steady-state responses of high-speed vehicles supported by discrete sleepers and segmented track slabs were studied.

The type of high-speed rail vehicle is basically determined, the vehicle status is similar, and the running speed is relatively constant. Therefore, the final rail corrugation has an obvious wavelength-fixed characteristic. In this paper, rail corrugation in the curve section of a high-speed rail line in China is selected as the research object. Based on the wheel-rail transient rolling contact finite element method, the cause of rail corrugation and the dynamic responses of wheelset-track system are studied. Firstly, a three-dimensional finite element model of wheelsettrack rolling contact is established by using the finite element software ABAQUS, and the rationality and effectiveness of the model are analyzed. Next, with the help of the above model, the wheel-rail contact stress states and relative slip characteristics are investigated to explain the cause of inner rail corrugation. Then, taking the rail/wheel vertical vibration acceleration as the output variable, the dynamic response characteristics of wheelset-track system are studied in order to understand the rail corrugation phenomenon more comprehensively. Finally, the parameter sensitivity analysis is carried out so as to control the generation and development of rail corrugation.

\section{ANALYSIS OF MEASURED RAIL CORRUGATION ON HIGH-SPEED RAIL}

Rail corrugation is a kind of periodic track irregularity. The track irregularity on the actual line is composed of random irregularities with different wavelengths, different phases and different amplitudes. It is a complex random process related to the mileage and traffic volume of the line. Therefore, the evaluation and expression of the track irregularity cannot be carried out only from the two data indexes of wavelength and wave depth, but must be described by the statistical parameters in the random theory. In this paper, the rail surface roughness level $L_{r}$ was selected to evaluate the rail corrugation in the measured section. The degree of rail corrugation was expressed in the form of one-third octave wavelength spectrum. The calculation of rail surface roughness level $L_{r}$ is shown in

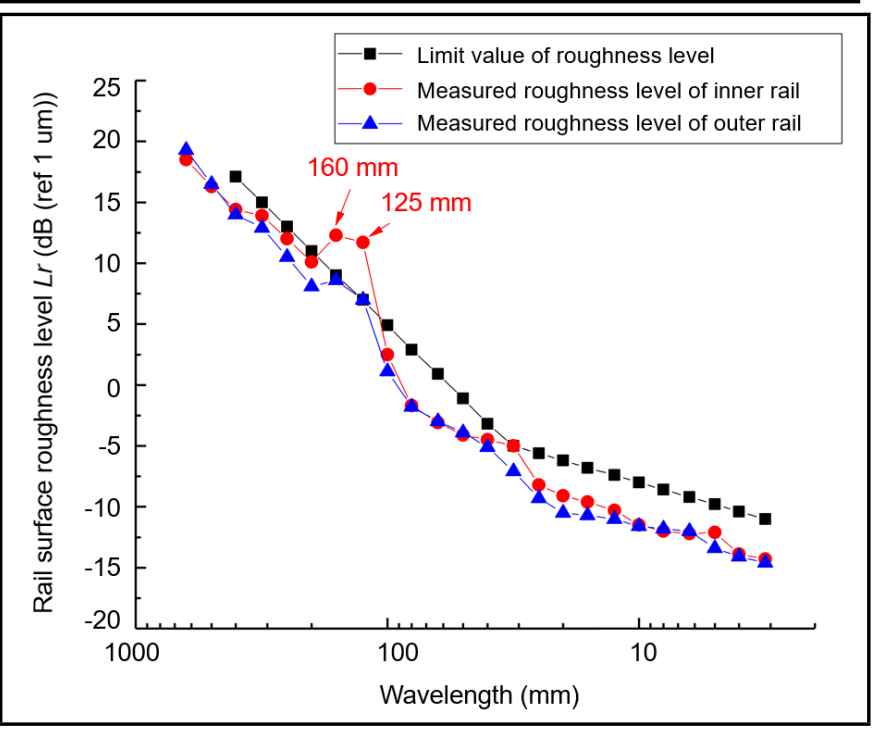

Figure 1. Limit values of rail surface roughness levels and measured roughness levels.

Eq. (1):

$$
L_{r}=20 \lg \left(r_{r m s} / r_{0}\right)
$$

where, $L_{r}$ was the spectrum value of rail surface irregularity, $d B ; r_{r m s}$ was the effective value of rail surface corrugation amplitude, $\mu m ; r_{0}$ was the reference value of rail surface roughness level, $=1 \mu \mathrm{m}$.

Figure 1 shows the allowable limit value of rail surface roughness level (shown by the black line in Fig. 1). Referring to the measurement and evaluation standard of rail corrugation: ISO $3095: 2013,{ }^{11}$ when the corresponding rail surface roughness level in the wavelength range was above the broken line, it was determined that there is rail corrugation with corresponding wavelengths. The measured section was a large radius curve line, the curve radius is $8900 \mathrm{~m}$, the design superelevation is $140 \mathrm{~mm}$, the line gradient was $10.5 \%$, the under-rail support is the ballastless track slab, and the average speed of CRH3 train passing this section is $300 \mathrm{~km} / \mathrm{h}$. Rail corrugation was measured by using the high-precision corrugation analysis trolley, which directly obtained the characteristic curve of rail surface corrugation varying with the mileage. According to Eq. (1), by converting the corrugation-mileage data into the form of one-third octave wavelength spectrum, as shown in the red line and blue line in Fig. 1, the rail corrugation characteristics in the measured section are analyzed.

It can be seen from Fig. 1 that the measured roughness levels of outer rail did not exceed the limit values of rail surface roughness levels in the whole wavelength range, indicating that there is no obvious corrugation on the outer rail. The measured roughness levels of inner rail were greater than the limit values of rail surface roughness levels at wavelengths of $125 \mathrm{~mm}$ and $160 \mathrm{~mm}$, which illustrated that there was corrugation phenomenon on the inner rail, and the characteristic wavelengths of inner rail corrugation were mainly $125 \mathrm{~mm}$ and $160 \mathrm{~mm}$. The above analysis outcomes were basically consistent with the field measurement results (the inner rail corrugation was obvious, and the outer rail corrugation is slight). The field picture of inner rail corrugation was shown in Fig. 2. 


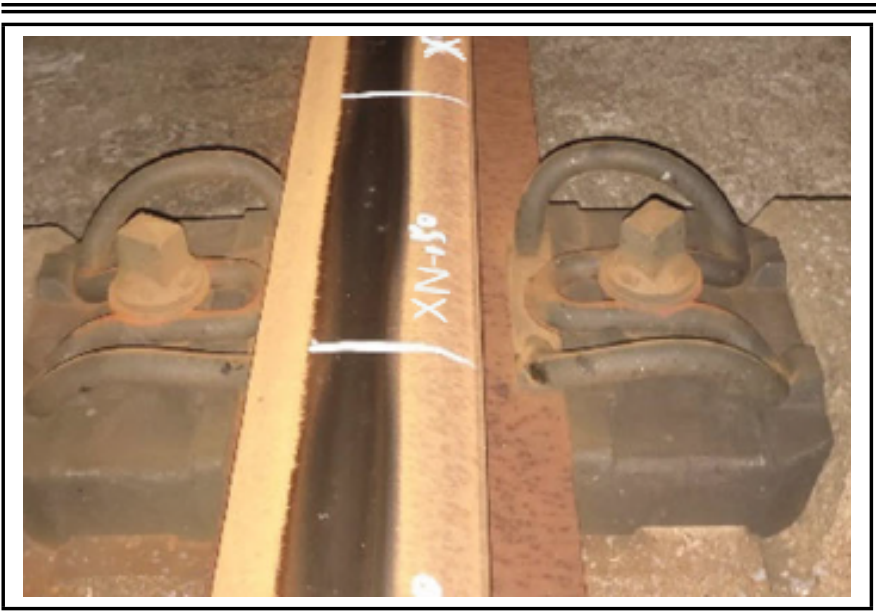

Figure 2. Inner rail corrugation of high-speed rail curve section.

Table 1. Material property of each component of wheelset-track system model.

\begin{tabular}{|c|c|c|c|}
\hline Component & Elastic modulus $(\mathrm{Pa})$ & Poisson's ratio & Density $\left(\mathrm{kg} / \mathrm{m}^{3}\right)$ \\
\hline wheelset & $2.1 \times 10^{11}$ & 0.3 & 7790 \\
\hline track slab & $3.45 \times 10^{10}$ & 0.25 & 2400 \\
\hline CA mortar & $8.0 \times 10^{9}$ & 0.2 & 1600 \\
\hline foundation & $2.55 \times 10^{10}$ & 0.25 & 2400 \\
\hline
\end{tabular}

\section{FINITE ELEMENT MODEL AND ANALYSIS METHOD}

\subsection{Finite Element Model of Wheel-Rail Transient Rolling Contact}

According to the actual line conditions of rail corrugation section, a three-dimensional wheelset-track transient rolling contact finite element model was established to analyze the rail corrugation phenomenon in the curve section of high-speed rail. The model schematic diagram is shown in Fig. 3, and the material parameters of each component of the model are shown in Table $1 .{ }^{12}$

For the finite element model of wheelset-track transient rolling contact established in this paper, the wheelset adopted CRH3 type wheelset structure, including three brake discs, which were fixed on the axle by interference fit. The nominal rolling circle diameter of the wheel was $860 \mathrm{~mm}$, and the wheel tread was LMA worn tread. Since the axle load of each wheelset was $155 \mathrm{kN},{ }^{12}$ the vertical suspension forces at both ends of the wheelset were set as $77.5 \mathrm{kN}$. Meanwhile, due to the large line curve radius, the lateral suspension force was relatively small, ${ }^{12,13}$ so the influence of the lateral suspension force on the calculation results will not be considered in this paper. Referring to the literature, ${ }^{12}$ the wheel-rail coefficient of friction was set as 0.5. Because the measured section is a large radius curve segment, the wheel-rail contact position is close to that on the straight line, as shown in Fig. 3 (b). ${ }^{14,15}$ The wheel-rail contact was assumed to be a single-point contact, and the contact point was located between the wheel tread and the rail head. The track model employed the ballastless track structure, which had the characteristics of strong stability, high smoothness and less maintenance, and is widely used in railway lines, especially in the high-speed rail. ${ }^{16-19}$ According to the conditions on-site, the typical CRTSII type track structure was selected, including rail, fastener, track slab, CA mortar, base plate and foundation. ${ }^{12}$ Because the track support layer of CRTSII type track structure was directly connected with the

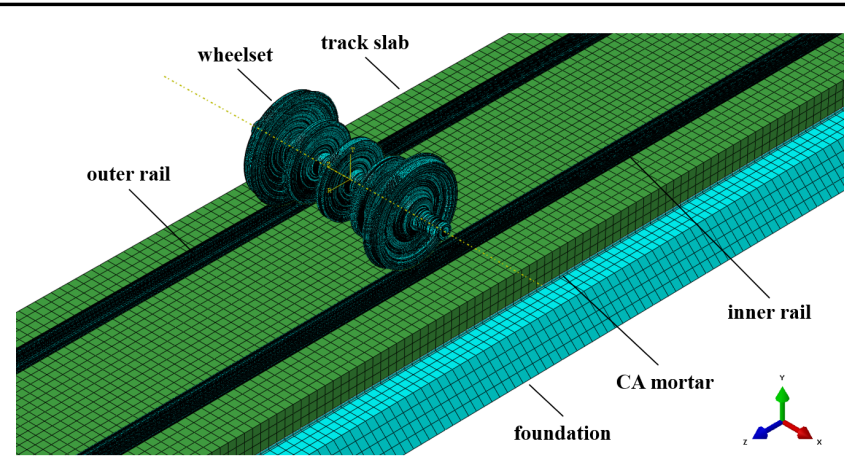

(a) General view of wheelset-track system.

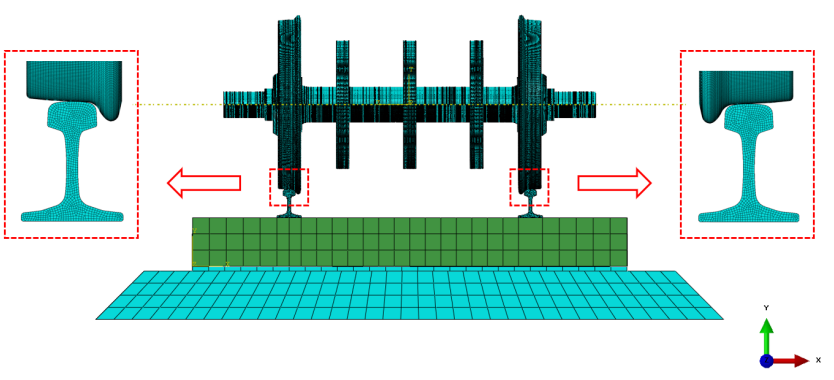

(b) Front view of wheelset-track system and wheel-rail contact detail.

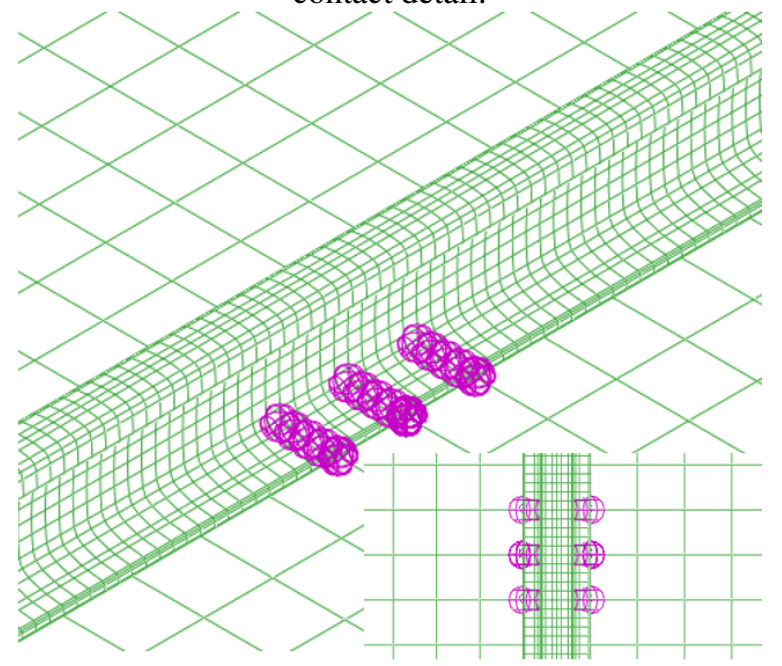

(c) Connection detail between rail and track slab.

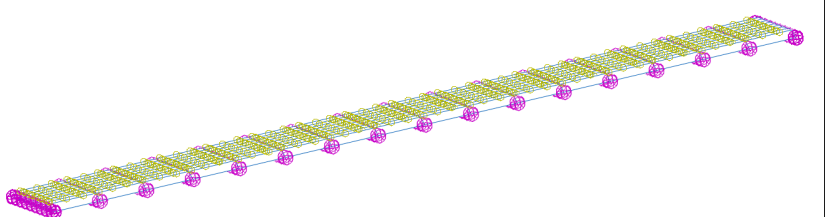

(d) Connection detail of grounding springs.

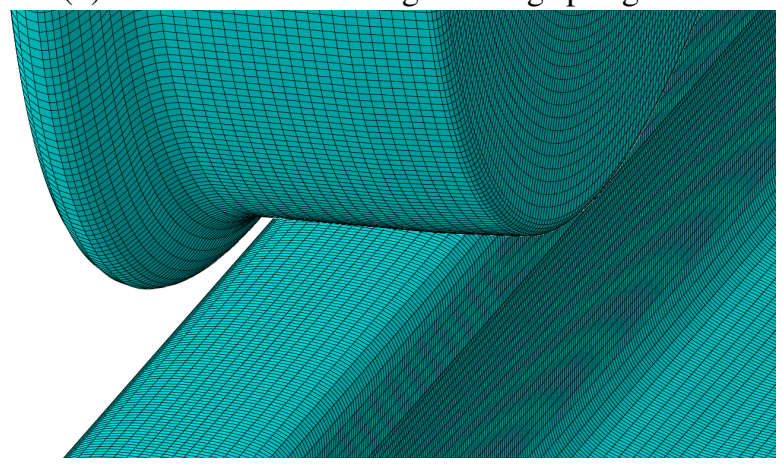

(e) Meshing detail of wheel-rail contact area. 


\begin{tabular}{|c|c|}
\hline Parameter & Value \\
\hline vertical stiffness of fastener $(\mathrm{N} / \mathrm{m})$ & $2.2 \times 10^{7}$ \\
\hline vertical damping of fastener $(\mathrm{Ns} / \mathrm{m})$ & $2.0 \times 10^{5}$ \\
\hline lateral stiffness of fastener $(\mathrm{N} / \mathrm{m})$ & $1.0 \times 10^{7}$ \\
\hline lateral damping of fastener $(\mathrm{Ns} / \mathrm{m})$ & $1.0 \times 10^{5}$ \\
\hline vertical supporting stiffness on foundation $(\mathrm{N} / \mathrm{m})$ & $1.9 \times 10^{8}$ \\
\hline vertical supporting damping on foundation $(\mathrm{Ns} / \mathrm{m})$ & $3.0 \times 10^{4}$ \\
\hline lateral supporting stiffness on foundation $(\mathrm{N} / \mathrm{m})$ & $5.0 \times 10^{7}$ \\
\hline lateral supporting damping on foundation (Ns/m) & $2.0 \times 10^{4}$ \\
\hline
\end{tabular}

track slab, there was no vibration reduction effect, thus it can be ignored in the track model and regarded as a whole with the track slab. The length of the track model was $36 \mathrm{~m}$, and the fastener spacing was $0.6 \mathrm{~m} .{ }^{20}$ The rail type was CHN60, and the rail, track slab, CA mortar layer and foundation were all simulated by solid elements. Because this paper mainly focuses on the cause of rail corrugation on high-speed rail rather than its development, the initial rail surface irregularity was not considered in the finite element model. The connection between the rail and the track slab as shown in Fig. 3 (c), that is, the fastener part, and the supporting effect on the foundation as shown in Fig. 3 (d), are simulated through spring-damping elements, ${ }^{21}$ and the corresponding stiffness and damping values are shown in Table $2 .^{12}$ Tie constraints were used between CA mortar layer and track slab, and between CA mortar layer and foundation. ${ }^{22}$ The bottom surface of foundation is completely constrained. The longitudinal (direction of wheelset movement) symmetric constraints were applied to both ends of rails, track slab, CA mortar layer and foundation. The whole model is meshed into 1753629 nodes and 1462138 elements, in which the mesh in the wheel-rail contact area was refined as shown in Fig. 3 (e), the element size was about $1 \mathrm{~mm}$, and the element size far away from the calculation area was about $50 \mathrm{~mm}$.

\subsection{Transient Dynamic Analysis Method}

Considering the wheel-rail friction coupling relationship, the transient dynamic analysis method was used to solve the dynamic responses of wheelset-track system. The transient dynamic analysis methods mainly included both the explicit time integration method and the implicit time integration method. ${ }^{23}$ The differences between them lied in the solution procedure of node velocity. The explicit time integration method solved the node velocity directly through the node calculation, while the implicit time integration method used the iterative approach to solve the equilibrium equations of the system. Because the explicit time integration method cannot analyzed the model with connecting springs and grounding springs, and when the time increment $\Delta t$ is less than one-tenth of the vibration period of the system concerned, the implicit time integration method can get more reliable results, therefore, the implicit solver ABAQUS/standard was employed to analyze the transient dynamic responses of wheelset-track system, and the analysis element type is C3D8R. In the process of using the implicit time integration method to solve the dynamic responses of wheelset-track system, the equilibrium equation of the system was founded at the end of each time increment step. The solution equations of node velocity and displacement are shown in Eq. (2) and Eq. (3): ${ }^{24}$

$$
\begin{gathered}
\dot{x}_{t+\Delta t}=\dot{x}_{t}+\Delta t\left[(1-\gamma) \ddot{x}_{t}+\gamma \ddot{x}_{t+\Delta t}\right] \\
x_{t+\Delta t}=x_{t} \Delta t \dot{x}_{t}+\Delta t^{2}\left[(0.5-\beta) \ddot{x}_{t}+\beta \ddot{x}_{t}+\beta \ddot{x}_{t+\Delta t}\right]
\end{gathered}
$$

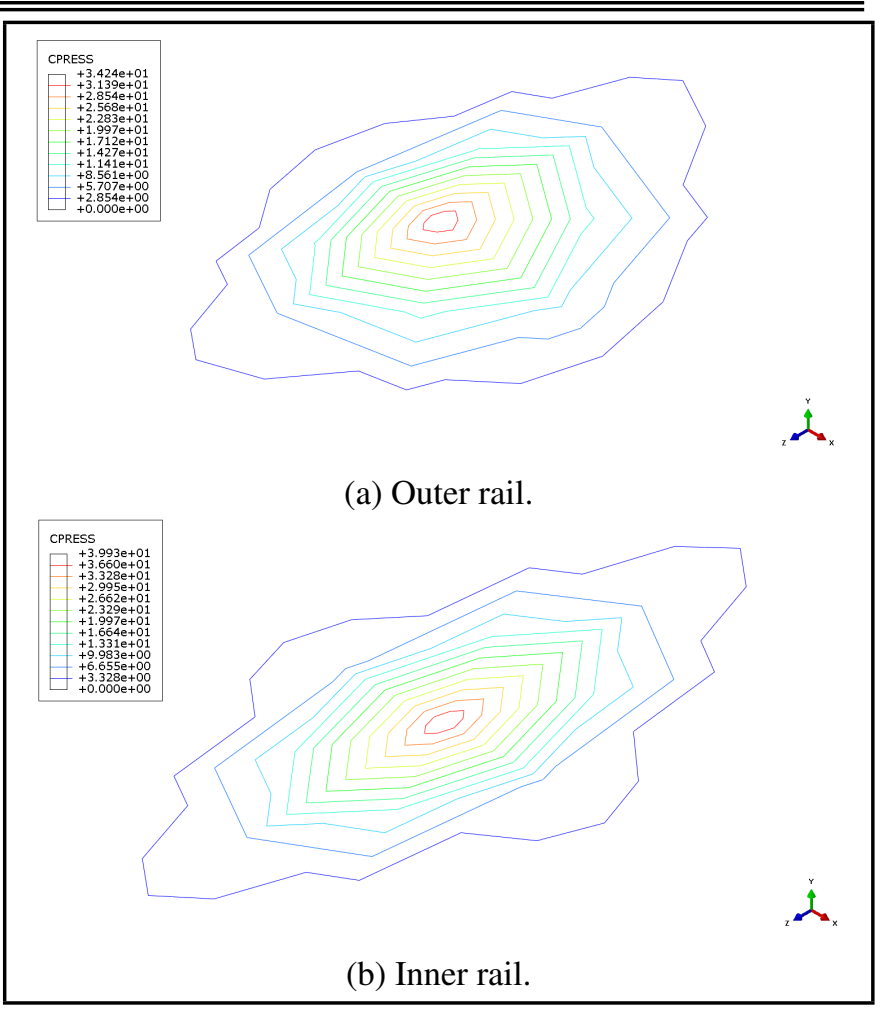

Figure 4. Wheel-rail normal contact stress.

where $\ddot{x}, \dot{x}$ and $x$ are the node acceleration, velocity and displacement respectively; $\beta=\left(1-\alpha^{2}\right) / 4, \gamma=0.5-\alpha$, $-1 / 3 \leq \alpha \leq 0$. Since the implicit time integration method obtains the node velocity and displacement at the end of the time increment step by solving the equilibrium equations of the system, the method was unconditionally stable. In addition, the occurrence frequency of rail corrugation was generally in the range of $20-1200 \mathrm{~Hz}$, so the integration step-size is set as $0.00005 \mathrm{s.}^{25}$

\section{CAUSE ANALYSIS OF RAIL CORRUGATION}

\subsection{Wheel-Rail Contact Stress State}

According to the actual line conditions, the running speed of the wheelset was set as $300 \mathrm{~km} / \mathrm{h}$, and the running time was set as $0.025 \mathrm{~s}$. The initial position of the wheelset was $17 \mathrm{~m}$ away from the end of the rail (opposite to the running direction of the wheelset). Based on the wheelset-track transient rolling contact model, through simulation and calculation, the corresponding wheel-rail contact stress distribution during vehicle operation was obtained, as shown in Fig. 4 and Fig. 5.

According to Fig. 4 and Fig. 5, the maximum normal contact stress of inner wheel-inner rail was $39.93 \mathrm{MPa}$, and the maximum tangential contact stress of inner wheel-inner rail was $15.97 \mathrm{MPa}$; the maximum normal contact stress of outer wheel-outer rail was $34.24 \mathrm{MPa}$, and the maximum tangential contact stress of outer wheel-outer rail was $13.70 \mathrm{MPa}$. By comparison, it was easy to find that the maximum nor$\mathrm{mal} /$ tangential contact stress of inner wheel-inner rail is greater than that of outer wheel-outer rail. The main reason for this was the excess superelevation of track structure, which leads to the wheel load deviation. According to the calculation Eq. (4) of the track equilibrium superelevation, when the vehicle speed was $300 \mathrm{~km} / \mathrm{h}$ and the curve radius was $8900 \mathrm{~m}$, the equilib- 


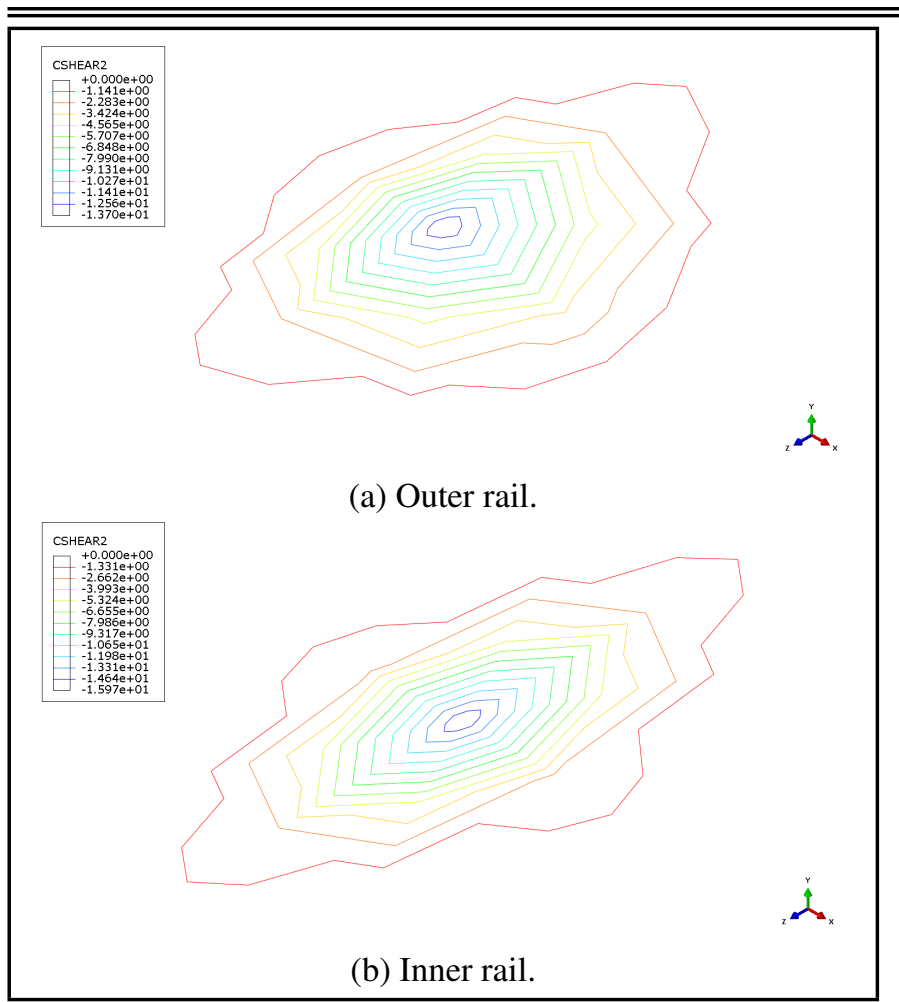

Figure 5. Wheel-rail tangential contact stress.

rium superelevation was about $120 \mathrm{~mm}$, while the design superelevation of the track model established in this paper was $140 \mathrm{~mm}$ (refer to the actual line), so the track structure was in the state of excess superelevation. When there was excess superelevation in the track structure, it will raise the load on the inner rail, resulting in the increase of the load on the inner rail and the decrease of the load on the outer rail, that is, the inner rail bears unbalanced load, which leads to the maximum normal/tangential contact stress of the inner wheel-inner rail being greater than that of the outer wheel-outer rail. The above result also verifies the rationality of the model. Because the wear of rail surface material was closely related to the stress it carried (including normal contact stress and tangential contact stress), and in the case of equal wheel-rail relative slip, the greater the stress of rail material bears, the more the wear was. Therefore, the inner rail unbalanced load caused by the excess superelevation of track structure may aggravate the development of rail wear. This conclusion is in line with that of the literature. ${ }^{23}$

$$
h_{b}=11.8 \frac{v^{2}}{R}
$$

where $h_{b}$ is the equilibrium superelevation, mm; $v$ is the vehicle running speed, $\mathrm{km} / \mathrm{h} ; R$ is the line curve radius, $\mathrm{m}$.

\subsection{Wheel-Rail Relative Slip Characteristics}

To further clarify the cause of rail corrugation, this section will analyze the characteristics of wheel-rail relative slip, and the calculated nephograms of wheel-rail relative slip on inner and outer rail sides are shown in Fig. 6. Note that the wheelrail relative slip refers to the total accumulated slip of rail surface node relative to wheel tread node at the contact interface, which can be extracted from the finite element model after calculation. It can be seen from Fig. 6 that the wheel-rail relative slip region on the inner rail side appeared periodically, and the distance between two adjacent slip regions on the inner rail

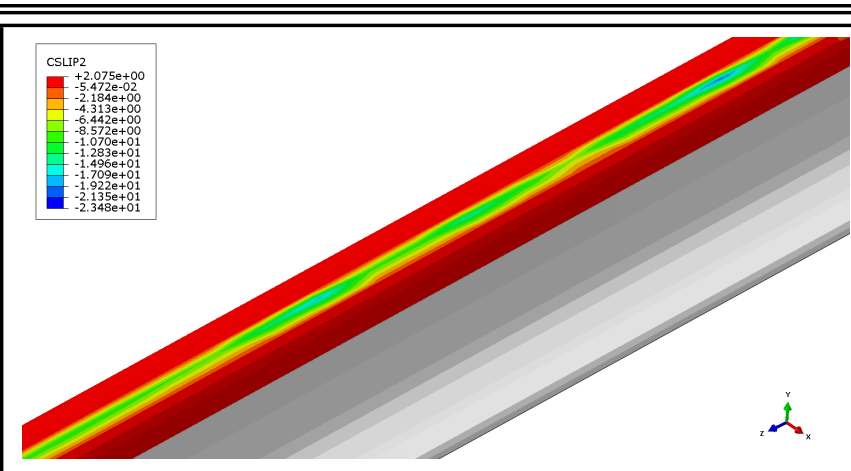

(a) Outer rail.

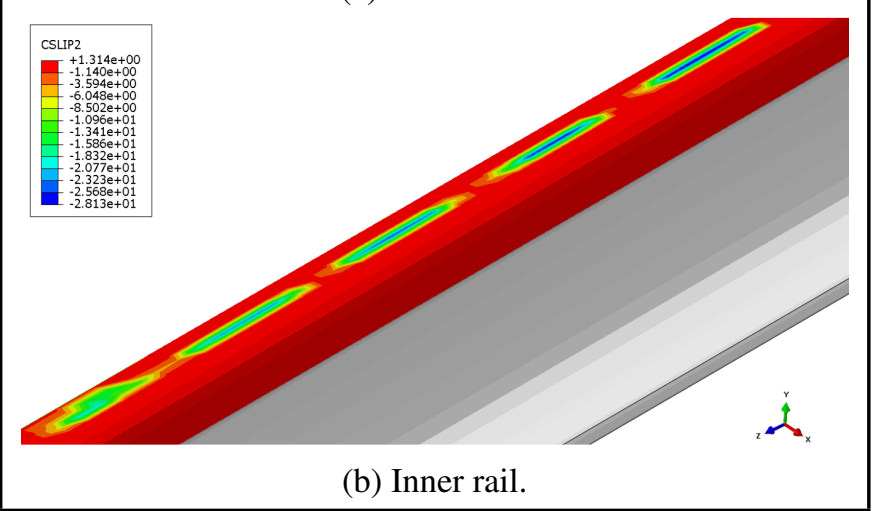

Figure 6. Wheel-rail relative slip nephograms.

was about $150 \mathrm{~mm}$, which was close to the characteristic wavelengths of $125 \mathrm{~mm}$ and $160 \mathrm{~mm}$ of inner rail corrugation in the measured section. The results show that the periodic variation of wheel-rail relative slip regions on the inner rail side plays a significant role in the formation of rail corrugation, and also verify the effectiveness of the model, which meets the accuracy requirement of engineering calculation. The periodicity of wheel-rail relative slip regions on the outer rail surface is not obvious, which indicates that the outer rail tends to form uniform wear, which is in accordance with the fact that the outer rail corrugation is slight in the measured section.

Moreover, by comparing the relative slip amplitudes on the inner and outer rail sides, it can be found that the maximum relative slip on the inner rail side is $28.13 \mathrm{~mm}$, and the maximum relative slip on the outer rail side is $23.48 \mathrm{~mm}$, that is, the maximum relative slip on the inner rail side is greater than that on the outer rail side. Combined with the conclusion in Section 4.1 (the maximum normal/tangential contact stress of inner wheel-inner rail is greater than that of outer wheel-outer rail), considering the work done by friction force (tangential contact stress), it can also be concluded that the wear on inner rail is more serious than that on outer rail. If the work done by friction force has the periodic characteristic, it will eventually lead to the formation of rail corrugation. Based on that, the cause of the periodic distribution of slip regions on the inner rail surface will be discussed from the aspect of the energy variation of wheelset-track system, so as to better explain the generation mechanism of rail corrugation.

The curves of internal energy, kinetic energy and total output energy of wheelset-track system during wheelset operation are shown in Fig. 7. Note that the internal energy, kinetic energy and total output energy of wheelset-track system can be directly obtained from the post-processing of the model after calculation, and the total output energy of wheelset-track system has the following expression: total output energy $=$ (inter- 
nal energy + viscous dissipated energy + frictional dissipated energy + kinetic energy + internal heat energy - work of the external force - work done by contact penalties - work done by constraint penalties - work done by propelling added mass (due to mass scaling) - external heat energy through external fluxes). It can be seen that the variation curves of internal energy, kinetic energy and total output energy of wheelsettrack system fluctuate greatly in the time interval of $0-0.005 \mathrm{~s}$, but the fluctuation range gradually tends to be fixed, which is mainly caused by the forced vibration of wheelset-track system induced by the sudden application of external force when the wheelset starts. With the increase of time, the influence of the forced vibration decreases gradually. When the wheelset runs to $0.005 \mathrm{~s}$, the fluctuation ranges of internal energy, kinetic energy and total output energy curves of wheelset-track system are almost constant, but they are still in the state of fluctuation. In particular, according to Fig. 7 (c), it can be seen that the total output energy of wheelset-track system has not reached equilibrium in the time interval of $0.0050 .025 \mathrm{~s}$, which illustrates that the wheelset-track system has been in the process of unstable energy exchange in this analysis interval, that is, the wheelset-track system has an unstable continuous oscillation. According to the analysis results of wheel-rail relative slip characteristics, both the inner and outer wheels slip on rails, which indicates that the tangential contact forces on the inner and outer rails are equal to the sliding friction forces in the wheel-rail slip region, that is, the tangential contact forces reach saturation. Meantime, referring to the literatures, ${ }^{14,24-30}$ it can be concluded that the unstable self-excited vibration of wheelset-track system under the situation of tangential contact force reaching saturation is the main reason for the formation of rail corrugation in the measured section, and the generation of unstable self-excited vibration is mainly related to the parameter matching of wheelset-track system. ${ }^{31-34}$ In addition, the reason for the obvious inner rail corrugation and the slight outer rail corrugation is mainly related to the excess superelevation state of track structure.

\section{SYSTEM DYNAMIC ANALYSIS}

The vertical vibration accelerations of rail and wheel were selected as output variables, and the corresponding time domain curves are extracted, as shown in Fig. 8, to study the dynamic response characteristics of wheelset-track system. The vertical vibration acceleration of the rail is determined by the upper surface of the inner rail bottom, and the vertical vibration acceleration of the wheel was determined by from the external surface of the inner wheel rim. It can be seen from Fig. 8 that the vertical vibration acceleration curve of the rail/wheel showed certain fluctuation characteristics in the whole time domain, and the fluctuation amplitude is relatively uniform. Furthermore, to explore the relationship between the dynamic responses of wheelset-track system and the formation of rail corrugation, the frequency domain characteristics of rail/wheel vertical vibration acceleration are analyzed. Through frequency domain transformation for the time domain data of vertical vibration acceleration, the corresponding frequency spectrum curve can be acquired, as shown in Fig. 9. It can be obtained that the dominant characteristic frequencies of vertical vibration accelerations of rail and wheel were all $561 \mathrm{~Hz}$. According to Eq. (5), when the running speed of the

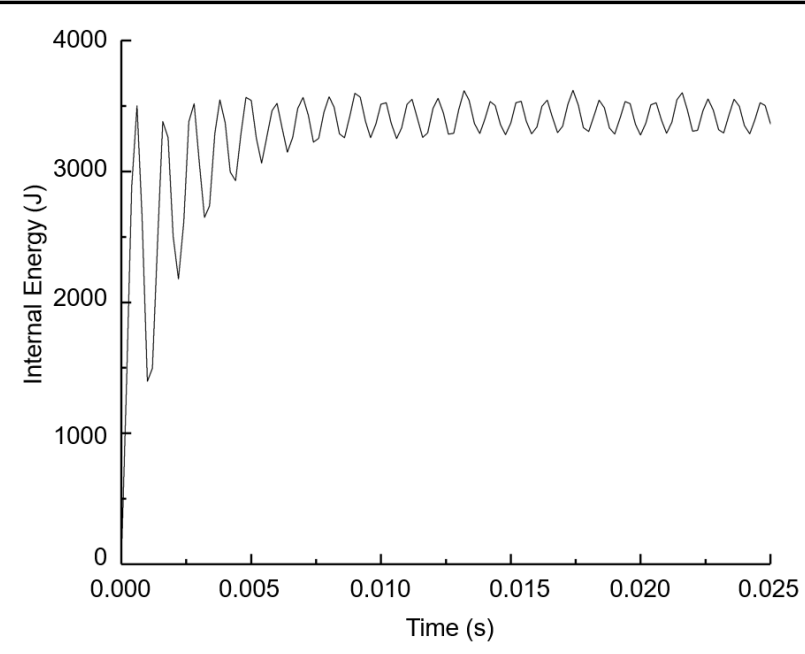

(a) Internal energy curve.

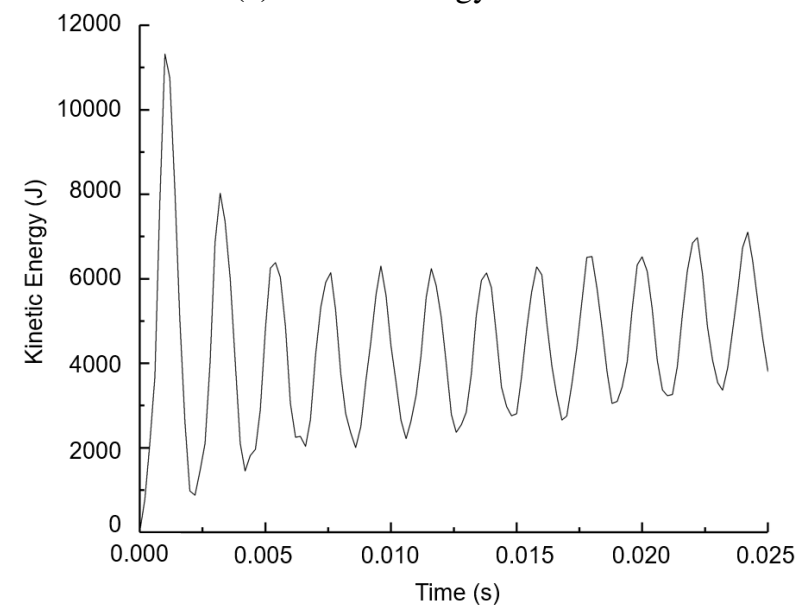

(b) Kinetic energy curve.

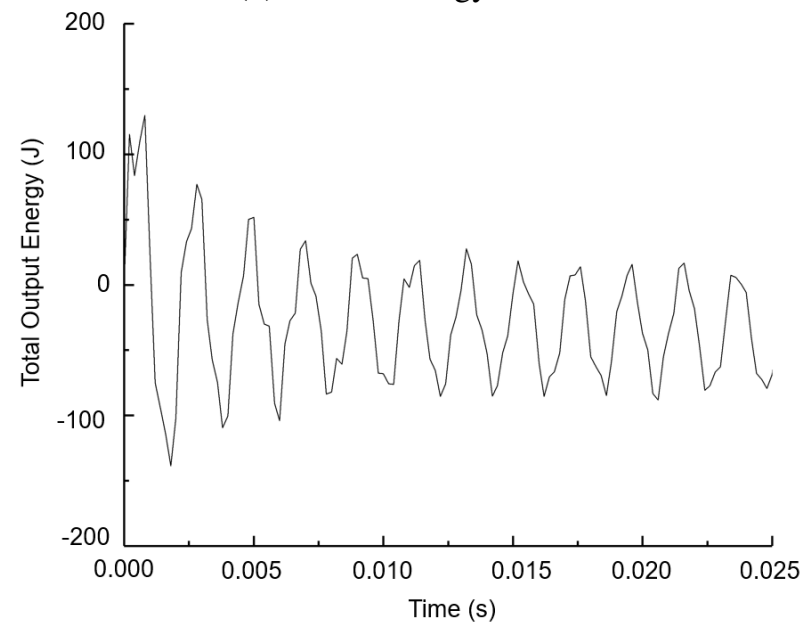

(c) Total output energy curve.

Figure 7. Energy curves of wheelset-track system.

wheelset was $300 \mathrm{~km} / \mathrm{h}$, the characteristic wavelength corresponding to the characteristic frequency of $561 \mathrm{~Hz}$ was about $148 \mathrm{~mm}$, which is close to the distance $(150 \mathrm{~mm})$ between the adjacent slip regions obtained in Section 4.2, and also close to the characteristic wavelengths $(125 \mathrm{~mm}$ and $160 \mathrm{~mm}$ ) of inner rail corrugation in the measured section, which further verifies the effectiveness of the model. The above results show that the resonance phenomenon (unstable vibration) occured in the wheelset-track system at $561 \mathrm{~Hz}$ during the operation of 


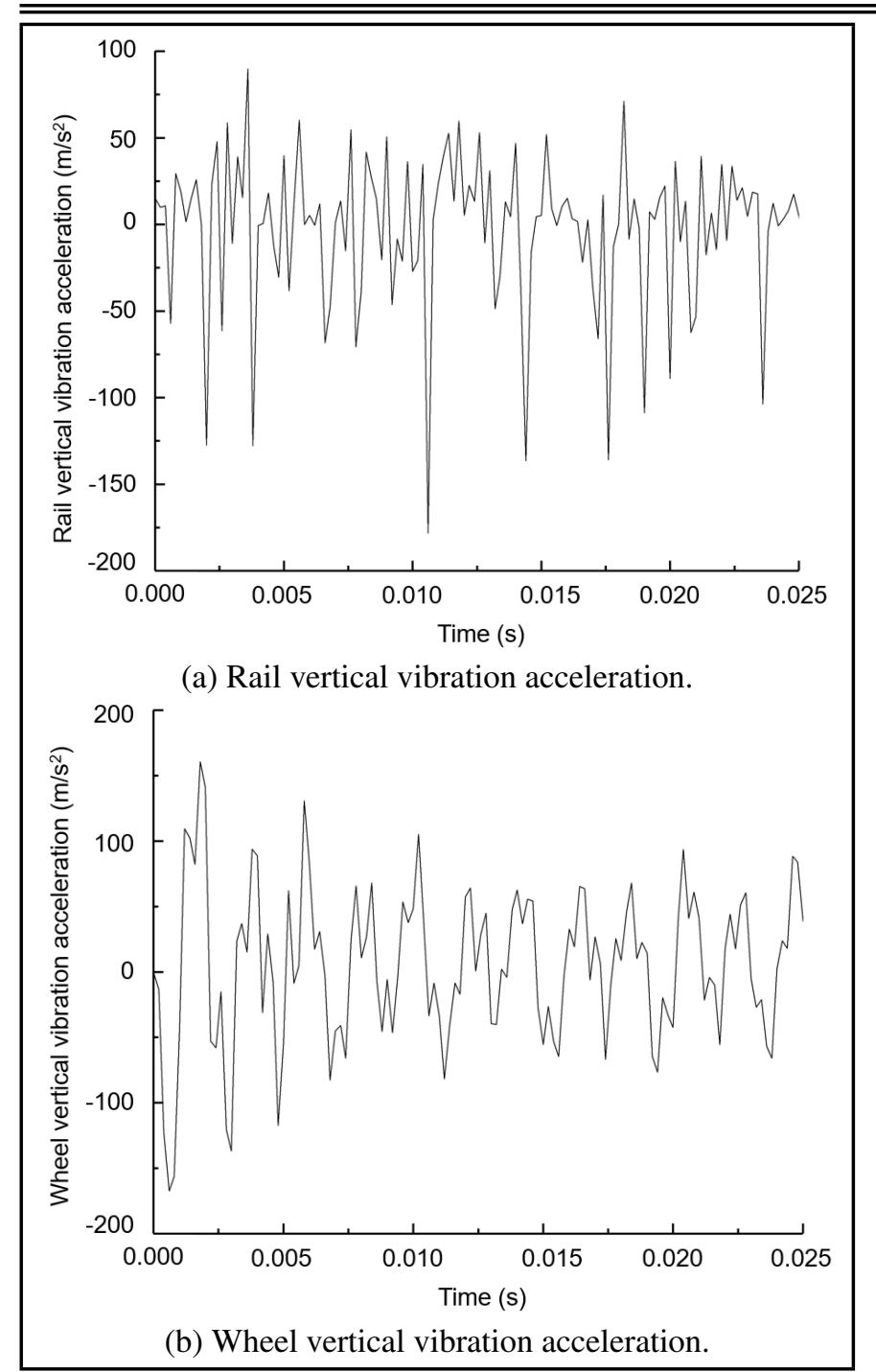

Figure 8. Time domain curves of vertical vibration accelerations.

wheelset, which brought about the increase of vibration amplitudes of rail and wheel, that is, the dynamic responses of the wheelset-track system became larger.

$$
\lambda=\frac{1000 v}{3.6 f}
$$

where, $\lambda$ was the wavelength, $\mathrm{mm} ; v$ was the running speed of wheelset, $\mathrm{km} / \mathrm{h} ; f$ was the frequency, $\mathrm{Hz}$.

The formation of rail corrugation is closely related to the structural parameters and operation parameters of wheelsettrack system (or vehicle-track system). Therefore, in order to control and slow down the generation and development of rail corrugation, parameter sensitivity analysis will be conducted in the following.

\section{PARAMETER SENSITIVITY ANALYSIS}

The vertical stiffness, lateral stiffness, vertical damping and lateral damping of fastener, coefficient of friction, and wheelset running speed are selected as the analysis parameters, and the wheel-rail maximum relative slip and periodicity of slip region are taken as the output indexes for sensitivity analysis. The results are shown in Table 3.

According to Table 3, the following results can be drawn,

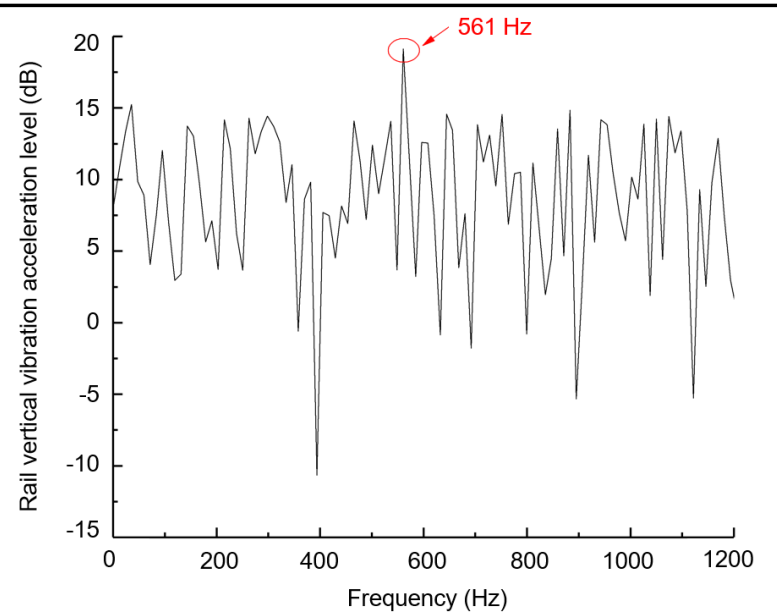

(a) Rail vertical vibration acceleration.

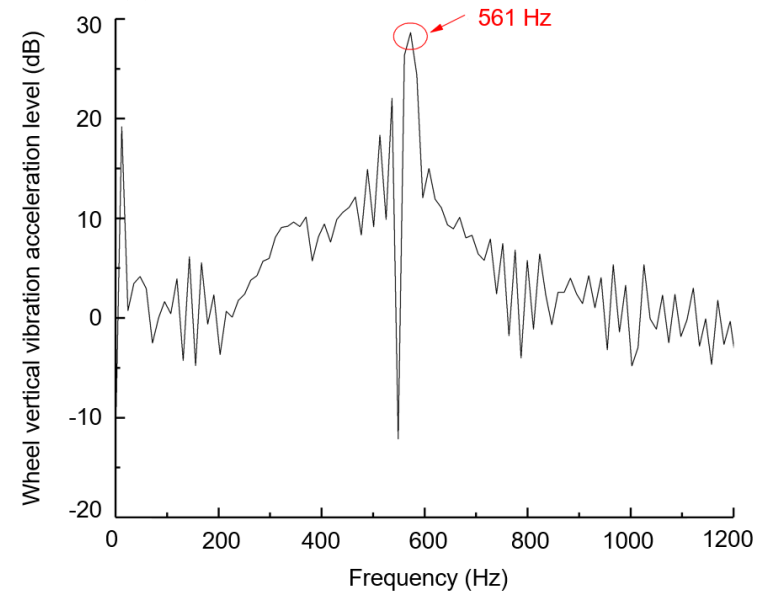

(b) Wheel vertical vibration acceleration.

Figure 9. Frequency domain curves of vertical vibration accelerations.

(1) Under the measured line conditions, with the increase of fastener vertical stiffness or the decrease of wheel-rail coefficient of friction, the wheel-rail maximum relative slip reduces obviously, and only the inner rail exists periodic slip regions. It shows that the fastener vertical stiffness and wheel-rail coefficient of friction have great influence on the development of inner rail corrugation, therefore, appropriately increasing the fastener vertical stiffness or decreasing the wheel-rail coefficient of friction can effectively control the evolution of rail corrugation.

(2) The lateral stiffness, vertical damping and lateral damping of fastener have little influence on the wheel-rail relative slip characteristics, which indicates that these parameters have little effect on the development of rail corrugation.

(3) The variation of wheelset running speed will affect the superelevation state of track structure, and then determine the occurrence probability and development degree of inner/outer rail corrugation. It is easy to induce inner rail corrugation when the track is in the state of excess superelevation (corresponding to working conditions of 250 $\mathrm{km} / \mathrm{h}$ and $300 \mathrm{~km} / \mathrm{h}$ ), but it is easy to cause outer rail corrugation when the track is in the state of deficient superelevation (corresponding to the working condition of 350 $\mathrm{km} / \mathrm{h}$ ). Meantime, the smaller the difference between the track superelevation and the equilibrium superelevation, the less the degree of rail corrugation. 
Z. Wang, et al.: ANALYSIS OF RAIL CORRUGATION CHARACTERISTICS ON HIGH-SPEED RAIL BASED ON TRANSIENT FINITE ELEMENT...

Table 3. Parameter sensitivity analysis results.

\begin{tabular}{|c|c|c|c|c|c|c|}
\hline \multirow{3}{*}{ Index } & \multicolumn{6}{|c|}{ Parameter } \\
\hline & \multicolumn{3}{|c|}{ vertical stiffness of fastener $(\mathrm{N} / \mathrm{m})$} & \multicolumn{3}{|c|}{ lateral stiffness of fastener $(\mathrm{N} / \mathrm{m})$} \\
\hline & $1.7 \times 10^{7}$ & $2.2 \times 10^{7}$ & $2.7 \times 10^{7}$ & $0.5 \times 10^{7}$ & $1.0 \times 10^{7}$ & $1.5 \times 10^{7}$ \\
\hline \multirow{2}{*}{ maximum relative slip (mm) } & 29.63 & 28.13 & 25.71 & 28.19 & 28.13 & 28.03 \\
\hline & (inner rail) & (inner rail) & (inner rail) & (inner rail) & (inner rail) & (inner rail) \\
\hline periodicity of slip region & inner rail exists & inner rail exists & inner rail exists & inner rail exists & inner rail exists & inner rail exists \\
\hline \multirow{2}{*}{ Index } & \multicolumn{3}{|c|}{ vertical damping of fastener $(\mathrm{Ns} / \mathrm{m})$} & \multicolumn{3}{|c|}{ lateral damping of fastener $(\mathrm{Ns} / \mathrm{m})$} \\
\hline & $1.5 \times 10^{5}$ & $2 \times 10^{5}$ & $2.5 \times 10^{5}$ & $0.5 \times 10^{5}$ & $1.0 \times 10^{5}$ & $1.5 \times 10^{5}$ \\
\hline \multirow{2}{*}{ maximum relative slip (mm) } & 28.09 & 28.13 & 28.15 & 28.11 & 28.13 & 28.13 \\
\hline & (inner rail) & (inner rail) & (inner rail) & (inner rail) & (inner rail) & (inner rail) \\
\hline periodicity of slip region & inner rail exists & inner rail exists & inner rail exists & inner rail exists & inner rail exists & inner rail exists \\
\hline \multirow{2}{*}{ Index } & \multicolumn{3}{|c|}{ coefficient of friction } & \multicolumn{3}{|c|}{ running speed $(\mathrm{km} / \mathrm{h})$} \\
\hline & 0.4 & 0.5 & 0.6 & 250 & 300 & 350 \\
\hline \multirow{2}{*}{ maximum relative slip (mm) } & 25.37 & 28.13 & 32.51 & 30.86 & 28.13 & 29.06 \\
\hline & (inner rail) & (inner rail) & (inner rail) & (inner rail) & (inner rail) & (outer rail) \\
\hline periodicity of slip region & inner rail exists & inner rail exists & inner rail exists & inner rail exists & inner rail exists & outer rail exists \\
\hline
\end{tabular}

\section{CONCLUSIONS}

(1) In the running process of wheelset, the maximum normal/tangential contact stress of inner wheel-inner rail is greater than that of outer wheel-outer rail. The main reason is that the inner rail is subject to the unbalanced load due to the excess superelevation of track structure, which indicates that the unbalanced load of inner rail may aggravate the development of rail wear, and also verifies the rationality of the model established in this paper.

(2) The wheel-rail relative slip region on the inner rail side appears periodically, and the distance between two adjacent slip regions is close to the characteristic wavelengths of measured inner rail corrugation, which illustrates that the periodic variation of slip regions on the inner rail surface plays an important role in the formation of rail corrugation. Meanwhile, the validity of the model is also verified. The periodicity of wheel-rail relative slip regions on the outer rail surface is not obvious, which shows that the outer rail tends to form uniform wear. This is consistent with the fact that the outer rail corrugation is slight in the measured section.

(3) The wheelset-track system is in the process of unstable energy exchange in the analysis interval, that is, the wheelset-track system has an unstable continuous oscillation. Combined with the analysis results of wheel-rail relative slip characteristics, it can be concluded that the unstable self-excited vibration of wheelset-track system when the tangential contact force reaches saturation is the main cause of rail corrugation.

(4) The dominant characteristic frequencies of vertical vibration accelerations of rail and wheel are all $561 \mathrm{~Hz}$, the corresponding characteristic wavelength $(148 \mathrm{~mm})$ is close to the calculated distance $(150 \mathrm{~mm})$ between the adjacent slip regions, and also close to the characteristic wavelengths $(125 \mathrm{~mm}$ and $160 \mathrm{~mm})$ of measured inner rail corrugation, which reflects that the resonance (unstable vibration) of wheelset-track system occurs at $561 \mathrm{~Hz}$ during the operation of wheelset, and brings about the increase of dynamic responses of wheelset-track system.

(5) The fastener vertical stiffness and wheel-rail coefficient of friction play important roles on the development of rail corrugation, and the running speed determines the occurrence probability of inner/outer rail corrugation by affecting the track superelevation state.

\section{ACKNOWLEDGEMENTS}

The research was supported by the National Natural Science Foundation of China (11772230).

\section{REFERENCES}

1 Si, D L., Li, W., and Du, X G., et al. Simulation analysis on mitigating rail corrugation for high speed railway, China Railway Science, 35(6), 79-83, (2014). https://dx.doi.org/10.3969/j.issn.1001-4632.2014.06.12

2 Zhi, S D. Modeling research on the grinding process of rail grinding vehicle, Beijing Jiaotong University, Beijing, (2015).

3 Lewis, R., Magel, E., and Wang, W J., et al. Towards a standard approach for the wear testing of wheel and rail materials, Proceedings of the Institution of Mechanical Engineers, Part F: Journal of Rail and Rapid Transit, 231(7), 760-774, (2017). https://dx.doi.org/10.1177/0954409717700531

${ }^{4}$ Fan, W G., Liu, Y M., and Li, J Y. Development status and prospect of rail grinding technology for high speed railway, Journal of Mechanical Engineering, 54(22), 184-193, (2018). https://dx.doi.org/10.3901/JME.2018.22.184

5 Jiang, $Z$ H., Zhao, G T., and Zhang, $H$ J., et al. Effects of vehicle and track key parameters on the rail corrugation of high-speed Railways, Journal of Mechanical Engineering, 54(4), 57-63, (2018). https://dx.doi.org/10.3901/JME.2018.04.057

6 Yan, Z J., Gao, C X., and Xu, X D., et al. Timefrequency characteristics analysis of periodic short wave disease of track for high-speed railway based on vehicle response, China Railway Science, 41(1), 10-17, (2020). https://dx.doi.org/10.3969/j.issn.1001-4632.2020.01.02

$7 \mathrm{Tu}, \mathrm{Y} \mathrm{H}$. Analysis of wheel-rail dynamic interaction of high speed railway, China Railway, 7,22-26, (2019). https://dx.doi.org/10.19549/j.issn.1001-683x.2019.07.022

8 Guo, T., Hou, Y Q., and Hu, X Y., et al. Influences of rail corrugations on dynamic performances of high speed vehicles, Railway Engineering, 59(3), 111-115, (2019). https://dx.doi.org/10.3969/j.issn.1003-1995.2019.03.28

9 Li, G., Zhang, Z C., and Zu, H L., et al. Experimental study on wheel-rail force response characteristics under typical track defects of high speed railway, China Railway Science, 40(6), 30-36, (2019). https://dx.doi.org/10.3969/j.issn.1001-4632.2019.06.04 
${ }_{10}$ Cai, W B. and Chi, M R. Study on steady-state responses of high-speed vehicle using infinite long track model, Shock and Vibration, 3, 6878252, (2020). https://dx.doi.org/10.1155/2020/6878252

${ }^{11}$ European Committee for Standardization. BS EN ISO 3095: 2013, Acoustics-Railway applications- Measurement of noise emitted by railbound vehicles, British Standards Institution, London, (2013).

$12 \mathrm{Yu}, \mathrm{M}$. Transient simulation for high-speed track/vehicle system and study on rail corrugation, China Academy of Railway Sciences, Beijing, (2019).

${ }^{13}$ Chen, Y C., Zhang, B J., and Zhang, N., et al. A condensation method for the dynamic analysis of vertical vehicle-track interaction considering vehicle flexibility, Journal of Vibration and Acoustics: Transactions of the ASME, 137(4), 041010, (2015). https://dx.doi.org/10.1115/1.4029947

${ }^{14}$ Chen, G X., Qian, W J., and Mo, J L., et al. Influence of the rail pad stiffness on the occurrence propensity of rail corrugation, Journal of Vibration Engineering and Technologies, 4(5), 455-458, (2016).

15 Fukagai, S., Brunskill, H P., and Hunter, A K., et al. Transitions in rolling-sliding wheel/rail contact condition during running-in, Tribology International, 149, 105679, (2020). https://dx.doi.org/10.1016/j.triboint.2019.03.037

16 Sadeghi, J., Liravi, H., and Esmaeili, M H. Experimental investigation on loading pattern of railway concrete slabs, Construction and Building Materials, 153, 481-495, (2017). https://dx.doi.org/10.1016/j.conbuildmat.2017.07.025

17 Sadeghi, J. and Esmaeili, M H. Effectiveness of track stiffness reduction in attenuation of metro induced vibrations received by historical buildings, Latin American Journal of Solids and Structures, 15(11), e142, (2018). https://dx.doi.org/10.1590/1679-78255252

18 Sainz-Aja, J., Pombo, J., and Tholken, D., et al. Dynamic calibration of slab track models for railway applications using full-scale testing, Computers and Structures, 228, 106180, (2020). https://dx.doi.org/10.1016/j.compstruc.2019.106180

${ }^{19}$ Gautier, P E. Slab track: review of existing systems and optimization potentials including very high speed, Construction and Building Materials, 92, 9-15, (2015). https://dx.doi.org/10.1016/j.conbuildmat.2015.03.102

${ }^{20} \mathrm{Li}$, X. Study on the mechanism of rail corrugation on subway track, Southwest Jiaotong University, Chengdu, (2012)

${ }^{21}$ Sadeghi, J. and Esmaeili, M H. Safe distance of cultural and historical buildings from subway lines, Soil Dynamics and Earthquake Engineering, 96, 89-103, (2017). https://dx.doi.org/10.1016/j.soildyn.2017.02.008

22 Dai, G L. and $\mathrm{Su}, \mathrm{M}$. Numerical simulation of interface delamination failure for prefabricated slab ballastless track, Journal of South China University of Technology (Natural Science Edition), 44(7), 102-107+122, (2016). https://dx.doi.org/10.3969/j.issn.1000-565X.2016.07.016
${ }^{23}$ Yang, Z. and Li, Z L. A numerical study on waves induced by wheel-rail contact, International Journal of Mechanical Sciences, 161-162, 105069, (2019). https://dx.doi.org/10.1016/j.ijmecsci.2019.105069

${ }^{24}$ Abubakar, A R. and Ouyang H. Complex eigenvalue analysis and dynamic transient analysis in predicting disc brake squeal, International Journal of Vehicle Noise and Vibration, 2(2), 143-155, (2006). https://dx.doi.org/10.1504/IJVNV.2006.011051

25 Cui, X L., Qian, W J., and Zhang, Q., et al. Forming mechanism of rail corrugation of a straight track section supported by Cologne-egg fasteners, Journal of Vibration and Shock, 35(13), 114-118+152, (2016). https://dx.doi.org/10.13465/j.cnki.jvs.2016.13.019

${ }^{26}$ Chen X. Research on the evolution mechanism of rail corrugation on tight curves in heavy-haul railway, Beijing Jiaotong University, Beijing, (2019).

27 Wu, B W., Chen, G X., and Kang, X., et al. Study on the origin of rail corrugation at a long downhill braking section based on friction-excited oscillation, Tribology Transactions, 63(3), 439-452, (2020). https://dx.doi.org/10.1080/10402004.2019.1707336

${ }^{28}$ Chen, G X., Zhang, S., and Wu, B W., et al. Field measurement and model prediction of rail corrugation, Proceedings of the Institution of Mechanical Engineers, Part F: Journal of Rail and Rapid Transit, 234(4), 381-392, (2020). https://dx.doi.org/10.1177/0954409719877318

${ }^{29} \mathrm{Wu}, \mathrm{B}$ W., Chen, G X., and Lv, J Z., et al. Effect of the axlebox arrangement of the bogie and the primary suspension parameters on the rail corrugation at the sharp curve metro track, Wear, 426-427, 1828-1836, (2019). https://dx.doi.org/10.1016/j.wear.2019.01.038

${ }^{30}$ Cui, X L., Yan, S., and Chen, G X. Field measurement and numerical simulation for rail corrugation in sector of fixed dual short sleeper, Journal of Vibration and Shock, 37(13), 171-176, (2018). https://dx.doi.org/10.13465/j.cnki.jvs.2018.13.027

${ }^{31}$ Xia, C G., Chen, G X., and Zhu, M H., et al. Effect of damped coating of wheel web on rail corrugation, Surface Technology, 49(3), 134-140, (2020). https://dx.doi.org/10.16490/j.cnki.issn.10013660.2020.03.017

${ }^{32}$ Zhang, Y H., Chen, G X., and Zhao, X N., et al. Influence of wheel web shape and rail gauge on rail corrugation, Lubrication Engineering, 45(2), 40-44, (2020). https://dx.doi.org/10.3969/j.issn.0254-0150.2020.02.008

${ }^{33}$ Yan, S., Zhao, X N., and Cui, X L., et al. Influence of wheel/rail contact parameters on rail corrugation, Lubrication Engineering, 43(11), 42-46, (2018). https://dx.doi.org/10.3969/j.issn.0254-0150.2018.11.008

${ }^{34}$ Cui, X L., Chen, G X., and Yang, H G. Influence of wheelset structure and fastener stiffness on rail corrugation, Journal of Southwest Jiaotong University, 52(1), 112-117, (2017). https://dx.doi.org/10.3969/j.issn.02582724.2017.01.016 